\title{
Thermomechanical Properties of Jute/Bamboo Cellulose Composite and Its Hybrid Composites: The Effects of Treatment and Fiber Loading
}

\author{
Fui Kiew Liew, ${ }^{1,2}$ Sinin Hamdan, ${ }^{1}$ Md. Rezaur Rahman, ${ }^{1}$ and Mohamad Rusop ${ }^{3}$ \\ ${ }^{1}$ Faculty of Engineering, Universiti Malaysia Sarawak, 94300 Kota Samarahan, Sarawak, Malaysia \\ ${ }^{2}$ Faculty of Applied Science, Universiti Teknologi MARA, 94300 Kota Samarahan, Sarawak, Malaysia \\ ${ }^{3}$ NANO-SciTech Centre (NST), Institute of Science, Universiti Teknologi MARA, Shah Alam, Selangor, Malaysia \\ Correspondence should be addressed to Fui Kiew Liew; liewsan2004@gmail.com
}

Received 16 January 2017; Revised 27 March 2017; Accepted 27 April 2017; Published 23 May 2017

Academic Editor: Peter Chang

Copyright (C) 2017 Fui Kiew Liew et al. This is an open access article distributed under the Creative Commons Attribution License, which permits unrestricted use, distribution, and reproduction in any medium, provided the original work is properly cited.

\begin{abstract}
Jute cellulose composite (JCC), bamboo cellulose composite (BCC), untreated hybrid jute-bamboo fiber composite (UJBC), and jute-bamboo cellulose hybrid biocomposite (JBCC) were fabricated. All cellulose hybrid composites were fabricated with chemical treated jute-bamboo cellulose fiber at 1:1 weight ratio and low-density polyethylene (LDPE). The effect of chemical treatment and fiber loading on the thermal, mechanical, and morphological properties of composites was investigated. Treated jute and bamboo cellulose were characterized by Fourier transform infrared spectroscopy (FTIR) to confirm the effectiveness of treatment. All composites were characterized by tensile testing, thermogravimetric analysis (TGA), and differential scanning calorimetry (DSC). Additionally, surface morphology and water absorption test was reported. The FTIR results revealed that jute and bamboo cellulose prepared are identical to commercial cellulose. The tensile strength and Young's modulus of composites are optimum at 10 weight percentage (wt\%) fibers loading. All cellulose composites showed high onset decomposition temperature. At $10 \mathrm{wt} \%$ fiber loading, JBCC shows highest activation energy followed by BCC and JCC. Significant reduction in crystallinity index was shown by BCC which reduced by $14 \%$. JBCC shows the lowest water absorption up to 43 times lower compared to UJBC. The significant improved mechanical and morphological properties of treated cellulose hybrid composites are further supported by SEM images.
\end{abstract}

\section{Introduction}

Cellulose is the world's most abundant natural raw material with renewable sources for composite fabrication. Natural cellulose fibers have attracted global researchers owing to their unique properties such as biodegradability, low weight, easy availability, easy processing, being environmental friendly, flexibility, high strength, and stiffness [1-3].

Jute is commonly grown in India, China, and Bangladesh. Jute fibers contain mainly cellulose (58 63\%), hemicellulose (20 24\%), and lignin (12 15\%) [4]. It has been used as packaging material, geotextiles, household textiles, and carpet backing. Bamboo is a fast-growing species and a highyield renewable resource. Bamboo fiber consists of cellulose (73.8\%), hemicellulose (12.5\%), lignin (10.1\%), pectin $(0.4 \%)$, and aqueous extract (3.2\%) [5]. Bamboo fibers have been widely used in the household, transport, and composite manufacturing industries [6]. However, all cellulose fibers have similar drawbacks which include being polar, hydrophilic in natural, low thermal stability and poor compatibility with polymer matrix. Those limitations contributed to weak fibermatrix interfacial bonding, leading to decrease in mechanical properties [7].

To improve the interfacial bonding, researchers have attempted various surface treatments, such as alkali treatment [8-10], silane treatment [11, 12], acetylation [13], and different coupling agents. Among various treatments, alkali treatment has been found to be most effective method [14, 15]. The surface treatments of cellulose fibers provide advantages which include increased hydrophobicity, increased surface roughness, reduced water uptake, and increased reactivity towards polymeric matrices $[16,17]$. Alkaline treatment or 


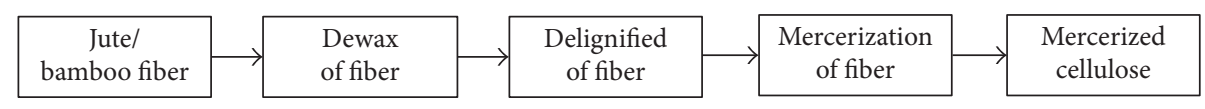

FIGURE 1: Flow diagram of cellulose preparation.

mercerization led to break down of fiber bundle into smaller fibers. Mercerization also modifies the lignin content by rupturing the ester bonds that form cross-links involving xylan and lignin, thus increasing the porosity of the lignocelluloses [18]. This treatment can effectively remove lignin and hemicellulose which indirectly increase cellulose contained in treated fiber. Mercerization increases the number of possible reactive sites and allows better fiber wetting [16]. As a result, mercerization had long-lasting effect on the mechanical properties of fibers, mainly on fiber strength and stiffness [19].

Hybrid cellulose composites are materials made from combining two or more different celluloses in a common matrix. Hybrid cellulose composites made up of two different cellulosic fibers are less common but they are potentially useful materials with respect to environmental concerns [20]. Hybrid cellulose composites fabrication by cellulosic fibers is economical and provides another dimension to the versatility of cellulosic fiber reinforced composites. The constituent fibers in a hybrid composite can be altered in many ways, leading to good mechanical properties [21]. Hybrid composites are one of the emerging fields that draw attention for application in various sectors ranging from automobile to the building industry. Previous research showed that cellulose composites have best mechanical performance at about 10-15 wt\% fiber loading [22, 23].

Pöllänen et al. (2013) studied the influence of the viscose fibers and the microcrystalline cellulose on the morphological, mechanical, and thermal expansion properties of high density polyethylene (HDPE) composite. The filler content of $5,10,20$, and $40 \mathrm{wt} \%$ was used. The interaction between the fillers and the matrix was improved with maleic anhydride grafted polyethylene. Both fillers increased Young's modulus and tensile strength of polyethylene with the highest values achieved by $40 \mathrm{wt} \%$ viscose fibers [24]. Both fillers show decreased coefficients of the linear thermal expansion of the HDPE matrix in the flow direction. Cellulose composites containing up to $10 \mathrm{wt} \%$ cellulose pulp fibers with low-density polyethylene (LDPE) were fabricated by Sdrobiş et al. (2012). Unbleached and bleached Kraft cellulose pulp fibers modified with oleic acid in cold plasma conditions have been used. It was found that thermal stability of cellulose pulp fibers composites is higher than that of pure LDPE [25]. Bleached cellulose pulp fibers are more efficient in enhancement of composites properties.

In the present work, the jute and bamboo cellulose had been extracted and treated with peracetic acid solution and then followed by mercerization. The effects of chemical treatment and cellulose fiber and hybrid cellulose fiber loading on thermal, mechanical, morphological, and water absorption properties of cellulose composites were investigated and reported. The outcome of investigation is expected to determine the suitability of composite for nonstructural and outdoor applications such as door trim panels, parts of automobile, and playground facilities.

\section{Materials and Methods}

Jute (Corchorus olitorius) and bamboo (Dendrocalamus asper) fibers were obtained from Bangladesh Jute Research Institute (BJRI), Dhaka, Bangladesh, and Forest Research Institute, Sarawak, Malaysia, respectively. Low-density polyethylene (LDPE) granula was obtained from the Siam Polyethylene Co., Ltd., Prakanong, Bangkok, Thailand. The density and the melting point were $0.935 \mathrm{~g} \cdot \mathrm{cm}^{-3}$ and between 105 and $125^{\circ} \mathrm{C}$, respectively. The chemicals used were toluene (Sigma Aldrich, St. Louis, MO, USA), commercial cellulose (Sigma Aldrich, St. Louis, MO, USA), ethanol (Sigma Aldrich, St. Louis, MO, USA), hydrogen peroxide (Qeric), acetic acid glacial (JT Baker, Center Valley, PA, USA), titanium (IV) oxide (JT Baker, Center Valley, PA, USA), and sodium hydroxide (Merck KgaA, Darmstadt, Germany). All chemicals were of analytical grade.

2.1. Natural Fiber Preparation. The jute fibers were cleaned and air-dried for $48 \mathrm{~h}$ under direct sunlight. The middle portion of the jute fiber was removed and chopped into approximately $10-\mathrm{mm}$ long and then oven-dried at $105^{\circ} \mathrm{C}$ for $24 \mathrm{~h}$. Finally, the sections were ground and sieved using a 100$\mu \mathrm{m}$ sieve. The length of the bamboo culm trim, excluding the bamboo internode, was $1 \mathrm{~m}$ in length. It was cut using a planner machine to produce chips and then ground to powdered form. The chips and powder mixture were dried in an oven at $70^{\circ} \mathrm{C}$ for $72 \mathrm{~h}$. The oven-dried samples were grinded and sieved, using a $100-\mu \mathrm{m}$ sieve, to obtain bamboo fibers with a mesh size of $100 \mu \mathrm{m}$.

2.2. Chemical Treatment of Jute and Bamboo Fiber. Jute and bamboo fiber were chemically treated to obtain treated cellulose. Initially, fibers were dewaxed. Then, cellulose fiber was obtained by oxidative delignification using a water solution containing acetic acid, hydrogen peroxide with titanium (IV) oxide, and $\mathrm{TiO}_{2}$ catalysts adopted Kuznetsov method [26]. Cellulose fiber is alkaline treated to obtain mercerized cellulose fiber. The details of chemical treatments flow are shown in Figure 1 and steps are explained below.

Dewaxing of Fiber. The dewaxing was done by applying the Leavitt-Danzer method. In this process, two types of chemical were used, namely, toluene $\left(\mathrm{C}_{6} \mathrm{H}_{5} \mathrm{CH}_{3}\right)$ and ethanol $\left(\mathrm{C}_{2} \mathrm{H}_{6} \mathrm{O}\right)$ with ratios of $2: 1(\mathrm{v} / \mathrm{v})$. The extraction process was done using the extraction column (Soxhlet extractor, round bottom flask, Liebig condenser, heater, membrane, and thermometer). Then, the jute/bamboo fibers were immersed 


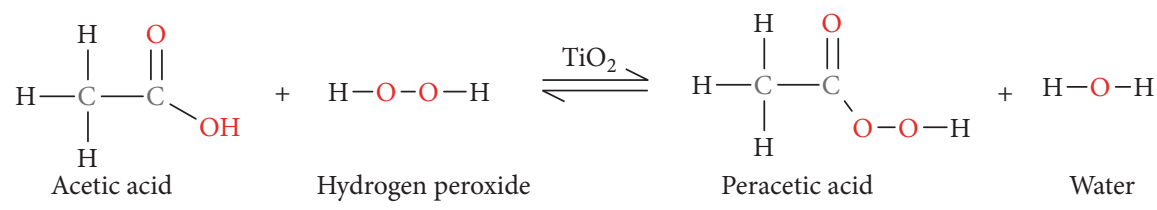

FIgURE 2: Peracetic acid solution reaction scheme.

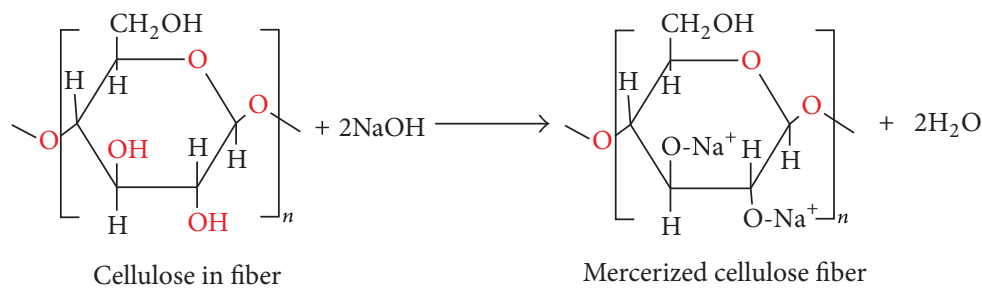

FIGURE 3: Mercerization reaction scheme.

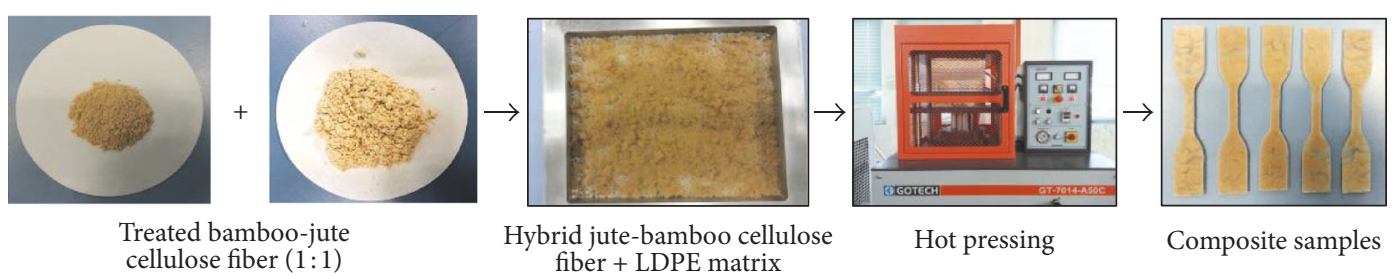

FIGURE 4: Flow of hybrid composite preparation.

in the extraction column. This process was continued for 2 hours at $250^{\circ} \mathrm{C}$. The collected fibers were later placed in the forced air convention oven for 24 hours at $75^{\circ} \mathrm{C}$ for drying overnight and were kept for delignification processes.

Delignification of Fiber. The delignification was done using peracetic acid solution which consists of $99.8 \mathrm{wt} \%$ acetic acid $\left(\mathrm{CH}_{3} \mathrm{COOH}\right)$ and $35 \mathrm{wt} \%$ hydrogen peroxide $\left(\mathrm{H}_{2} \mathrm{O}_{2}\right)$ in the present of titanium (IV) oxide $\left(\mathrm{TiO}_{2}\right)$ catalyst in a round bottom vector vessel. The reaction scheme is shown in Figure 2.

Then, the dewaxed jute/bamboo fibers were placed in the round bottom vessel. This process was continued for 2 hours at $130^{\circ} \mathrm{C}$. After this, the collected fibers were carefully washed and placed in the forced air convention oven for 24 hours at $70^{\circ} \mathrm{C}$.

Mercerization. Delignified fiber was immersed into alkaline solution to dissolve the pectin and hemicelluloses. $6 \mathrm{wt} \%$ sodium hydroxide was used to treat the cellulose fiber in a flask. The mixture was stirred using autoshaker at $150 \mathrm{rpm}$, heated to $80^{\circ} \mathrm{C}$ for 2 hours, and stopped after 8 hours of stirring. The mixture was rinsed with deionized (DI) water. The treated product was then filtered using Buchner flask and rinsed with DI water until the $\mathrm{pH}$ level reaches 7 and was freeze-dried at $-85^{\circ} \mathrm{C}$ for 48 hours. The treated fiber was then ground using a shear grinder for $10 \mathrm{~min}$ to obtain fine mercerized cellulose fiber. The detail of reaction is shown in Figure 3.
2.3. Composite Preparation. Both mercerized jute and bamboo cellulose were kept in a convection oven at $100^{\circ} \mathrm{C}$ for 24 hours prior to composite fabrication. Desired weight fraction of hybrid cellulose fibers was equally distributed using sieve on correct weight fraction of LDPE laminate sheet to produce hybrid cellulose fibers composite. The LDPE laminate sheet was put in an aluminum mold using sandwich method and then placed in an electric hot press set at $180^{\circ} \mathrm{C}$ with $3.45 \mathrm{MPa}$ (500 psi) for $45 \mathrm{~min}$. Aluminum mold was cooled down under pressure for 1 hour and the prepared specimens were taken out to label. Specimens were cut into composite samples by tensile cutter. Table 1 shows the details of hybrid composites by weight percentages. Flow of hybrid composite preparation was shown in Figure 4.

\section{Characterization Methods}

3.1. Fourier Transform Infrared Spectroscopy (FTIR). The FTIR spectra were obtained using a spectrometer (spectrum 100, Perkin Elmer, Waltham, MA). The obtained spectra are described in the Results and Discussion. The transmittance range of the scan was 4000 to $650 \mathrm{~cm}^{-1}$.

3.2. Tensile Test. Tensile testing was conducted according to the ASTM D 638-10 (2010) [27] testing standard using a universal testing machine (MSC-5/500, Shimadzu Company Ltd., Japan) at a crosshead speed of $5 \mathrm{~mm} \cdot \mathrm{min}^{-1}$. The dimensions of the specimens were $115 \mathrm{~mm}(L) \times 6.5 \mathrm{~mm}(W) \times$ 
TABLE 1: Hybrid composite by weight percentage.

\begin{tabular}{|c|c|c|c|c|c|}
\hline \multirow{2}{*}{ Number } & \multirow{2}{*}{ Hybrid composite } & \multicolumn{3}{|c|}{ Composition by weight (wt.\%) } & \multirow{2}{*}{ Sample ID } \\
\hline & & Jute cellulose & Bamboocellulose & LDPE & \\
\hline \multirow{4}{*}{1} & \multirow{4}{*}{ Untreated jute-bamboo/LDPE composites } & 2.5 & 2.5 & 95 & F05UJBC \\
\hline & & 5.0 & 5.0 & 90 & F10UJBC \\
\hline & & 7.5 & 7.5 & 85 & F15UJBC \\
\hline & & 10.0 & 10.0 & 80 & F20UJBC \\
\hline \multirow{4}{*}{2} & \multirow{4}{*}{ Jute cellulose/LDPE composites } & 5 & - & 95 & F05JCC \\
\hline & & 10 & - & 90 & F10JCC \\
\hline & & 15 & - & 85 & F15JCC \\
\hline & & 20 & - & 80 & F20JCC \\
\hline \multirow{4}{*}{3} & \multirow{4}{*}{ Bamboo cellulose/LDPE composites } & - & 5 & 95 & F05BCC \\
\hline & & - & 10 & 90 & F10BCC \\
\hline & & - & 15 & 85 & F15BCC \\
\hline & & - & 20 & 80 & F20BCC \\
\hline \multirow{4}{*}{4} & \multirow{4}{*}{ Jute-bamboo cellulose/LDPE composites } & 2.5 & 2.5 & 95 & F05JBCC \\
\hline & & 5.0 & 5.0 & 90 & F10JBCC \\
\hline & & 7.5 & 7.5 & 85 & F15JBCC \\
\hline & & 10.0 & 10.0 & 80 & F20JBCC \\
\hline
\end{tabular}

$3.1 \mathrm{~mm}(T)$. Five rectangular specimens were tested and the average value was reported for each series.

3.3. Thermogravimetric Analysis (TGA). Thermogravimetric measurements were performed using a Perkin Elmer Pyris 1 TGA system. All measurements were obtained under a nitrogen flow rate of $20 \mathrm{~mL} \cdot \mathrm{min}^{-1}$ over a temperature range of 50 to $600^{\circ} \mathrm{C}$. Then, an oxygen flow rate of $20 \mathrm{~mL} \cdot \mathrm{min}^{-1}$ and a temperature range of 600 to $700^{\circ} \mathrm{C}$ was applied, while maintaining a constant heating rate of $20^{\circ} \mathrm{C} \cdot \mathrm{min}^{-1}$. Three specimens were tested and the average value was reported.

3.4. Differential Scanning Calorimetry (DSC). The DSC tests were conducted using a differential scanning calorimeter (DSC; 8000, Perkin Elmer). Temperature programs for dynamic tests were run from 50 to $180^{\circ} \mathrm{C}$ at the heating rate of $20^{\circ} \mathrm{C} \cdot \mathrm{min}^{-1}$ under a $20 \mathrm{~mL} \cdot \mathrm{min}^{-1}$ nitrogen atmosphere. The degree of crystallinity was calculated according to the following formula.

$$
\text { Degree of crystallinity, } \chi_{c}=\frac{\Delta H_{m}}{w \Delta H_{m}^{o}} \times 100,
$$

where $\Delta H_{m}$ is enthalpy of fusion, $w$ is the weight fraction of polymeric matrix in the composite, and $\Delta H_{m}^{o}=290 \mathrm{~J} / \mathrm{g}$ (heat of fusion for $100 \%$ crystalline LDPE).

3.5. Scanning Electron Microscopy (SEM) Analysis. The surface morphology was examined using a scanning electron microscope (TM 3030 pitch emission, Hitachi, Tokyo, Japan). The SEM specimens were sputter-coated with gold using auto-fine coater (JFC-1600, Joel Ltd.). The micrographs with a 500-time resolution were presented in the Results and Discussion.
3.6. Water Absorption Test. In order to measure the water absorption characteristics of the composites, rectangular specimens were prepared. The water absorption test was conducted according to ASTM D570-99 [28]. The test specimens were immersed in a beaker containing $100 \mathrm{~mL}$ of deionized water at room temperature $\left(27^{\circ} \mathrm{C}\right)$ for 22 days. The initial weights of the samples were determined. After 24-hour interval, samples were taken out from the beaker, wiped and dried, and weighed immediately. The percentages of water absorbed by the samples were calculated using the following formula. Three replicates were tested for each set and average data was recorded.

$$
\text { Water absorption }=\frac{\text { Final weight }- \text { Original weight }}{\text { Original weight }}
$$

\section{Results and Discussions}

4.1. Fourier Transform Infrared Spectroscopy (FTIR). FTIR composition of bamboo fiber, jute fiber, commercial cellulose, jute cellulose, and bamboo cellulose was shown in Figure 5.

Figure 5 showed bamboo fiber and jute fiber were having similar peak intensity. Both bamboo and jute fiber consist of cellulose, hemicellulose, and lignin; therefore peak intensities are identical. However, there were still differences among bamboo fiber and jute fiber peak. Only jute fiber showed peak at $1324 \mathrm{~cm}^{-1}$, which is attributed to the $\mathrm{CH}_{2}$ bending. Both jute and bamboo fibers show peak at $1738 \mathrm{~cm}^{-1}$ represented either the acetyl and uronic ester groups or the ester linkage of carboxylic group of the ferulic and p-coumeric acids of hemicelluloses $[29,30]$. The absence of this peak is observed in jute and bamboo cellulose, indicating the removal of most of the hemicellulose. The peak at $1242.4 \mathrm{~cm}^{-1}$ region is due to the stretching of phenolic hydroxyl groups in lignin [31]. Total disappear of this peak in jute and bamboo cellulose 


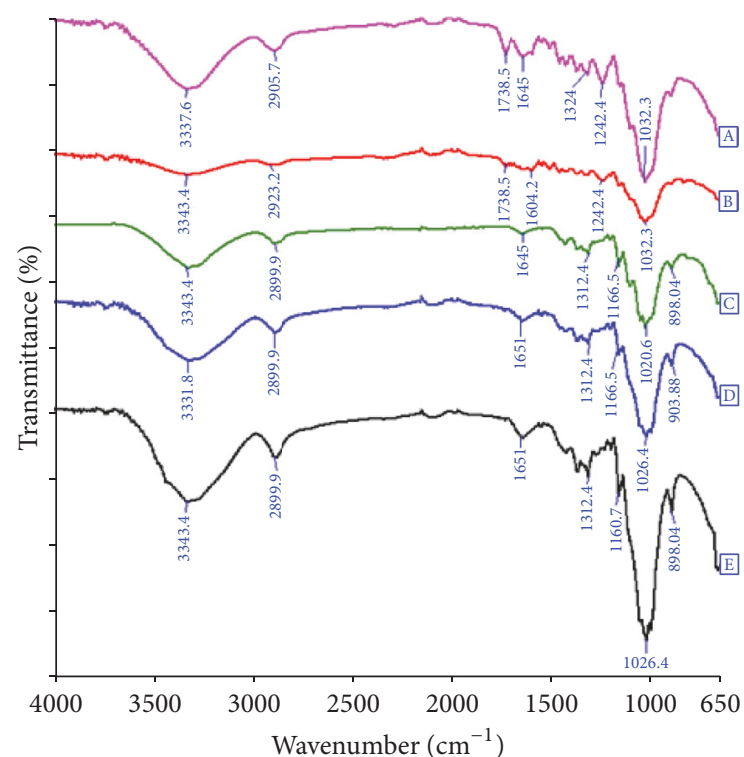

Figure 5: Wavelengths in FTIR of (A) jute fiber, (B) bamboo fiber, (C) commercial cellulose, (D) jute cellulose, and (E) bamboo cellulose.

samples revealed that lignin is removed. On the other hand, all cellulose samples show peak at $1166-1160 \mathrm{~cm}^{-1}$ region assigned as $\mathrm{C}-\mathrm{O}-\mathrm{C}$ stretching attributed to the $\beta-(1 \rightarrow 4)$ glycosidic linkage in cellulose [32].

Figure 5 also shows all cellulose with broad peak intensity band at $3343-3331 \mathrm{~cm}^{-1}$ attributed to $\mathrm{O}-\mathrm{H}$ stretching vibration. The peaks at $2923-2900 \mathrm{~cm}^{-1}$ and $1324-1312 \mathrm{~cm}^{-1}$ regions are characteristics of $\mathrm{C}-\mathrm{H}$ stretching and $-\mathrm{CH}_{2}$ bending, respectively. The peak at $1651-1646 \mathrm{~cm}^{-1}$ is attributed to the $\mathrm{H}-\mathrm{O}-\mathrm{H}$ stretching vibration of absorbed water in carbohydrate. The peak at $903-898 \mathrm{~cm}^{-1}$ region is related to glycosidic $-\mathrm{C}_{1}-\mathrm{H}$ deformation, a ring vibration, and $-\mathrm{O}-\mathrm{H}$ bending. These characters imply the $\beta$-glycosidic linkages between the anhydroglucose units in cellulose. The rise of intensity peak at $1026-1020 \mathrm{~cm}^{-1}$ region confirms that the cellulose content increases due to chemical treatment [33]. Both jute and bamboo cellulose show identical peaks compared to commercial cellulose. This further confirms that hemicelluloses and lignin in both jute and bamboo fiber were well removed during the chemical treatment.

4.2. Tensile Properties. The tensile strength and Young's modulus of UJBC, JCC, BCC, and JBCC hybrid composite by weight percentages are shown in Figures 6(a) and 6(b), respectively. The results indicated that all treated cellulose composites have significant high tensile strength and Young's modulus compared to untreated hybrid composite (UJBC). Hybrid cellulose composite with $10 \mathrm{wt} \%$ fiber loading shows highest tensile strength and Young's modulus among the sample series tested. The tensile strength gradually decreases when fiber loading is greater than $10 \mathrm{wt} \%$.

Among the cellulose hybrid composites, it is obviously shown that JBCC at $10 \mathrm{wt} \%$ was the optimized hybrid composite which increases tensile strength and Young's modulus by $157 \%$ and $195 \%$, respectively. The significant increase of tensile properties in JBCC is contributed by great improvements of interfacial adhesion between the treated hybrid cellulose fibers and LDPE matrix. The removal of hemicelluloses in hybrid cellulose fibers further enhances fiber rearrangement in composite which led to effective loads transfer [34]. JCC and BCC show similar tensile strengths which increase by $130 \%$ and $126.5 \%$, respectively. On the other hand, Young's modulus of BCC increased by $144 \%$ is much higher than JCC which only increases by $64.3 \%$. High resistance of elastic deformation on BCC attributed to high stiffness of bamboo cellulose in composite. Smaller cross-section of bamboo cellulose enhanced the stiffness of the composites [35]. The strong interface bonding between bamboo cellulose and LDPE enables effective stresses distribution on composite and contributed to high Young's modulus.

It is worth noting that all UJBC series show decreasing trend of mechanical properties with increased hybrid fibers loading. The incompatibility of hydrophilic fibers with hydrophobic polymer matrix causes relative weak fibersmatrix interfacial adhesion. Untreated hybrid fibers also exhibit poor resistance to moisture and led to high water absorption and subsequently contributed to poor mechanical properties of UJBC composites.

The stress-strain graph of UJBC, JCC, BCC, and JBCC composite at $10 \mathrm{wt} \%$ fiber loading is shown in Figure 7. The results revealed that all treated cellulose composites have high stress with greater strain compared with UJBC. The removal of hemicellulose and lignin in fiber provides strong adhesion between fiber and matrix. It contributed to enhancing strain by greater elongation of composites.

4.3. Thermogravimetric Analysis (TGA). The thermogravimetric analysis of UJBC, JCC, BCC, and JBCC hybrid composites at $10 \mathrm{wt} \%$ fiber loading was summarized in Table 2. Previous studies have found that there is no degradation of jute-bamboo hybrid composite up to $300^{\circ} \mathrm{C}$ [36]. Above this temperature, the decomposition takes place and thermal stability decreased.

UJBC sample showed that low onset decomposition started at $304.9^{\circ} \mathrm{C}$. Low onset decomposition of UJBC was mainly contributed by decomposition of hemicellulose [37]. On the other hand, all treated cellulose hybrid composites showed significant high onset decomposition temperature ranging from 346 to $415^{\circ} \mathrm{C}$. Relative high onset decomposition was due to high thermal resistance of treated cellulose fibers in hybrid composite. The high onset decomposition also confirms that hemicellulose was well removed in cellulose composites. There is no significant difference between untreated hybrid composite and treated cellulose hybrid composite related to major decomposition. The major decomposition of hybrid composite occurs between $511^{\circ} \mathrm{C}$ and $529^{\circ} \mathrm{C}$ involving $\alpha$-cellulose and LDPE resin [38]. At above $545^{\circ} \mathrm{C}$, final decomposition takes place. The final decomposition of F10JCC, F10BCC, and F10JBCC showed remaining weight of $5.1 \%, 3.2 \%$, and $3.5 \%$, respectively. The final remaining weight was mainly due to char formation. 


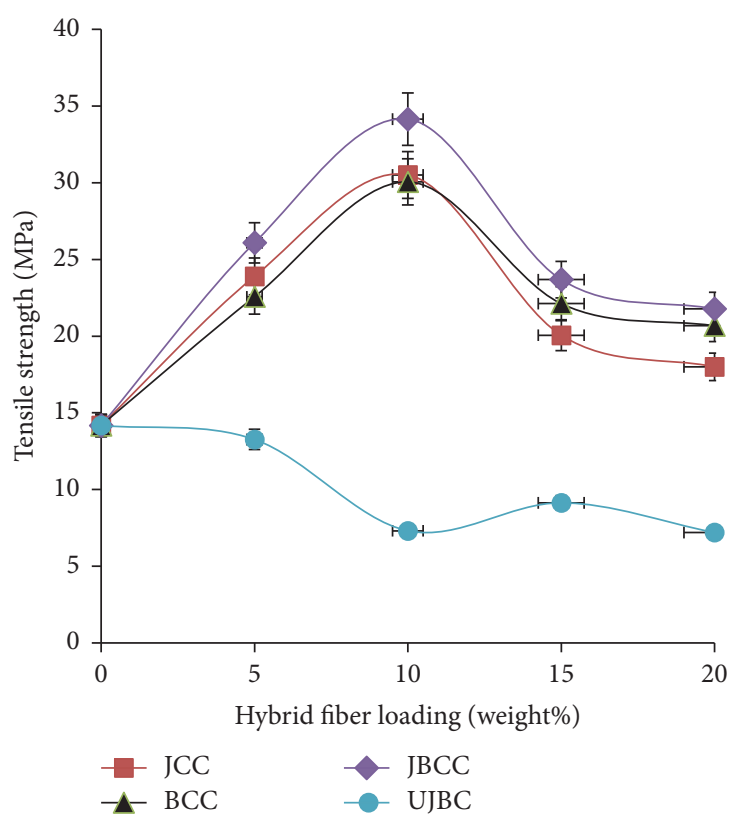

(a)

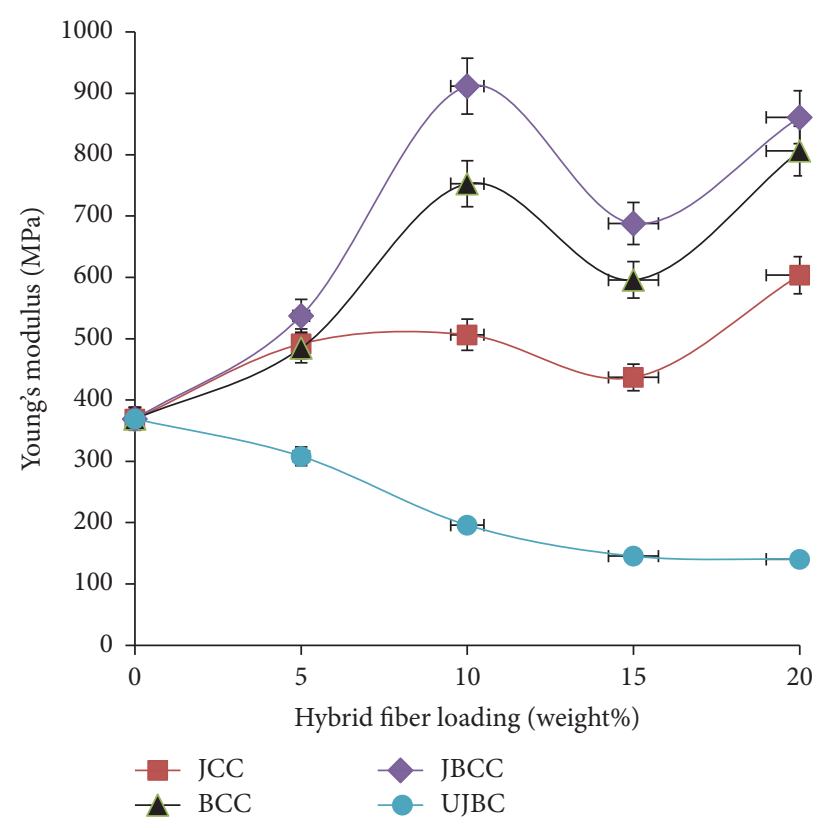

(b)

FIGURE 6: (a) Tensile strength of composite at different fiber loading. (b) Young's modulus of composite at different fiber loading.

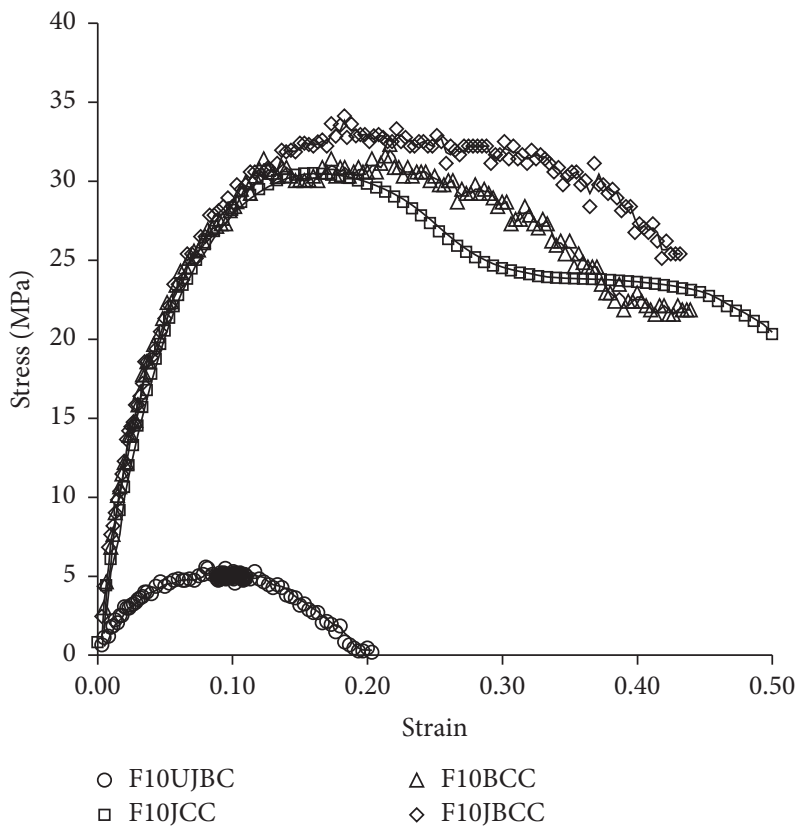

FIGURE 7: Stress-strain graph of hybrid composite at $10 \mathrm{wt} \%$ fiber loading.

The activation energy $\left(E_{a}\right)$ was calculated from TGA graphs using Broido equation [39] as given below:

$$
\ln \left(\ln \frac{1}{y}\right)=\frac{E_{a}}{R T}+\text { constant }
$$

where $y$ is the fraction of undecomposed nonvolatilized material, $T$ is the absolute temperature (in Kelvin), and $R$ is the gas constant $\left(8.314 \mathrm{~J} \mathrm{~mol}^{-1} \mathrm{~K}^{-1}\right)$. The values of $y$ have been taken from the TGA data. The values of $\ln (\ln (1 / y))$ were plotted on $y$-axis, while the temperatures as $1 / T$ (in Kelvin scale) were plotted on $x$-axis. Finally, from the slope of the trend line, the activation energy of the composite was calculated.

Table 2 shows that all treated cellulose composites obtain higher activation energy compared to F10UJBC. Among those composites, F10JBCC shows 2.5 times higher activation energy followed by F10BCC and F10JCC which are 2.0 and 1.1 times, respectively. The higher value of activation energy indicates the higher thermal stability of composite [40]. Higher activation energy in treated cellulose hybrid composite was attributed to rough surface and pores on the cellulose fibers become more prominent, which give better adhesion with the matrix [41].

4.4. Differential Scanning Calorimetry (DSC). The melting characteristic of $10 \mathrm{wt} \%$ cellulose composite is showed in Table 3. From Table 3, all cellulose and its hybrid composites show higher initial melting temperature compared to F10UJBC.

The crystallinity index was reduced from $55.9 \%$ for neat LDPE to $41.9 \%-50.3 \%$ for treated cellulose hybrid composites. Shortening of composite solidification time due to presence of cellulose fiber and the surface energy of fibers becoming closer to the surface energy of the matrix are reasons of reduced crystallinity index [42]. Significant reduction in crystallinity index was shown by F10BCC which reduced by $14 \%$. The result revealed that F10BCC has better fiber-matrix interfacial bonding which further supports high Young's modulus results. On the other hand, F10UJBC, F10JBCC, and F10JCC show a marginal reduction in crystallinity index of 
TABLE 2: Comparison of activation energy among hybrid composites at $10 \mathrm{wt} \%$ fiber loading.

\begin{tabular}{lccccccc}
\hline Samples & $T_{i}\left({ }^{\circ} \mathrm{C}\right)^{\mathrm{a}}$ & $T_{\mathbf{m}}\left({ }^{\circ} \mathrm{C}\right)^{\mathrm{b}}$ & $\underline{T}_{f}\left({ }^{\circ} \mathrm{C}\right)^{\mathrm{c}}$ & $W_{T i}(\%)^{\mathrm{d}}$ & $W_{T m}(\%)^{\mathrm{e}}$ & $W_{T f}(\%)^{\mathrm{f}}$ & $\begin{array}{c}\text { Activation energy, } \\
E_{a}(\mathrm{KJ} / \mathrm{mol})\end{array}$ \\
\hline F10UJBC & 304.9 & 525.2 & 550.5 & 99.1 & 19.3 & 2.8 & 64.55 \\
F10JCC & 355.7 & 511.0 & 553.1 & 97.9 & 28.6 & 5.1 & 3.2 \\
F10BCC & 346.4 & 524.5 & 545.1 & 99.0 & 22.0 & 32.96 & 129.86 \\
F10JBCC & 415.0 & 528.9 & 564.6 & 98.3 & 32.6 & 3.5 \\
\hline
\end{tabular}

${ }^{\mathrm{a}}$ Temperature corresponding to the onset of decomposition. ${ }^{\mathrm{b}}$ Temperature corresponding to maximum rate of mass loss. ${ }^{\mathrm{c}}$ Temperature corresponding to the end of decomposition. ${ }^{\mathrm{d}}$ Mass loss at temperature corresponding to the onset of decomposition. ${ }^{\mathrm{e}}$ Mass loss at temperature corresponding to the maximum rate of mass loss. ${ }^{\mathrm{f}}$ Mass loss at temperature corresponding to the end of decomposition.

TABLE 3: Melting characteristics of neat LDPE, UJBC, JCC, BCC, and JBCC at $10 \mathrm{wt} \%$ cellulose fiber loading.

\begin{tabular}{lccccc}
\hline Specimen & $\begin{array}{c}\text { Initial } \\
\text { melting } \\
\text { temperature } \\
\left({ }^{\circ} \mathrm{C}\right)\end{array}$ & $\begin{array}{c}\text { Peak } \\
\text { melting } \\
\text { temperature } \\
\left({ }^{\circ} \mathrm{C}\right)\end{array}$ & $\begin{array}{c}\text { Final } \\
\text { melting } \\
\text { temperature } \\
\left({ }^{\circ} \mathrm{C}\right)\end{array}$ & $\begin{array}{c}\text { Heat flow } \\
\Delta H_{m}\left(\mathrm{Jg}^{-1}\right)\end{array}$ & $\begin{array}{c}\text { Crystallinity } \\
\chi_{C}\end{array}$ \\
\hline Neat LDPE & 119.44 & 131.30 & 136.08 & 162.10 & $55.9 \%$ \\
\hline F10UJBC & 117.56 & 129.43 & 134.64 & 118.41 & $45.3 \%$ \\
F10JCC & 119.15 & 128.46 & 132.64 & 131.38 & $50.3 \%$ \\
F10BCC & 120.81 & 131.90 & 136.61 & 109.39 & $41.9 \%$ \\
F10JBCC & 119.54 & 130.10 & 134.82 & 120.91 & $46.3 \%$ \\
\hline
\end{tabular}

$\Delta H_{m}$ : enthalpy of fusion and $\chi_{C}$ : degree of crystallinity.

$9.9 \%, 9.6 \%$, and $5.6 \%$, respectively. It is worth noting that all DSC results for F10JBCC show a value between F10JCC and F10BCC. Those results indicated that F10JBCC hybrid composite shows average melting characteristic combination of F10JCC and F10BCC which is following rule of mixtures for hybrid composite [43].

4.5. Scanning Electron Microscopy (SEM) Analysis. Figure 8 shows SEM images of the cross-section surface of UJBC, JCC, BCC, and JBCC at $10 \mathrm{wt} \%$ fiber loading after tensile test. Figure 8(a) shows the delamination of F10UJBC. There were some microcracks because of the relatively weak interfacial bonding among the fibers and the matrix. Poor adhesion between the untreated hybrid fibers and the matrix creates further voids spaces around fibers in the hybrid composite [44].

Figure 8(b) shows the well-bonded jute cellulose composite. The good interfacial bonding between jute cellulose and LDPE matrix contributed to high tensile strength and modulus. Strong interfacial bonding was observed in F10JCC. Micrographs revealed that the jute cellulose fibers smoothly distributed in of LDPE resin.

Figure 8(c) shows a well-bonded interface between the bamboo cellulose fiber and LDPE matrix with some minor voids observed. This strong interfacial bond among cellulose fiber-LDPE matrix contributed to a higher tensile strength and modulus. This was mainly attributed to an elimination of the hydroxyl groups from chemical surface modified cellulose fibers.

Figure $8(\mathrm{~d})$ shows strong bonding between the jutebamboo cellulose fiber and LDPE matrix. The hydrophobic characteristics of treated hybrid cellulose fibers and well bonding of LDPE both strengthen the fibers-matrix interfacial adhesion. Relative minor microvoids appear between fiber and matrix interfacial.

4.6. Water Absorption Test. Figure 9 showed that water absorption of UJBC, BCC, JBCC, and JCC of $10 \mathrm{wt} \%$ cellulose fibers loading for 22 days. The untreated hybrid fiber composite (UJBC) showed highest water absorption rate up to $30.2 \%$ in this duration. Water absorption rate of UJBC starts to saturate after 11 days. High water absorption was results of poor wettability and adhesion between hydrophilic fibers-LDPE [45]. Untreated fibers are hydrophilic with many hydroxyl group $(-\mathrm{OH})$. The high percentage of $-\mathrm{OH}$ group in fibers tend to show low moisture resistance. This leads to dimensional variation of UJBC and poor interfacial bonding between the fiber and matrix. This also caused microcracks and voids formation in UJBC which trap and absorb greater percentage of water. As the microcracks propagated, capillarity and transport of water molecules via microcracks become active [46].

Among treated hybrid composites, F10JBCC shows the lowest water absorption rate of $0.7 \%$. F10JBCC water absorption saturated after 10 days. The mercerization treatment reduced the polar groups in fiber by replacing the hydroxyl groups on the surfaces of fibers [47]. The low water absorption rate in F10JBCC is contributed by good adhesion among treated hybrid fibers-matrix composite. Good interfacial adhesion bonding among treated cellulose fiber-matrix reacts to retard water entering cellulose fiber. F10JCC attained a saturation level after 6 days with water absorption of $1.9 \%$. It is worth noting that F10BCC shows highest water absorption rate among treated cellulose hybrid composites. The water 


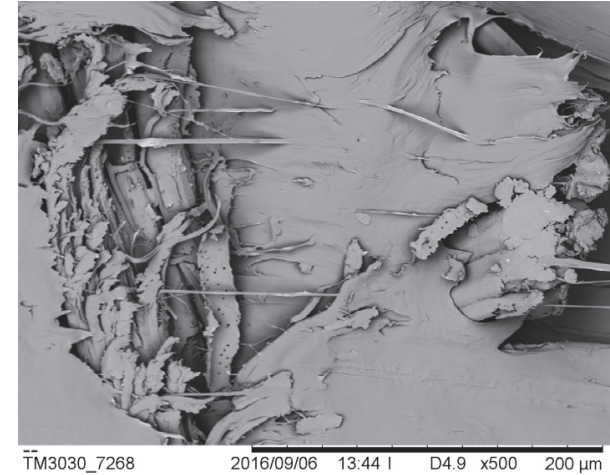

(a)

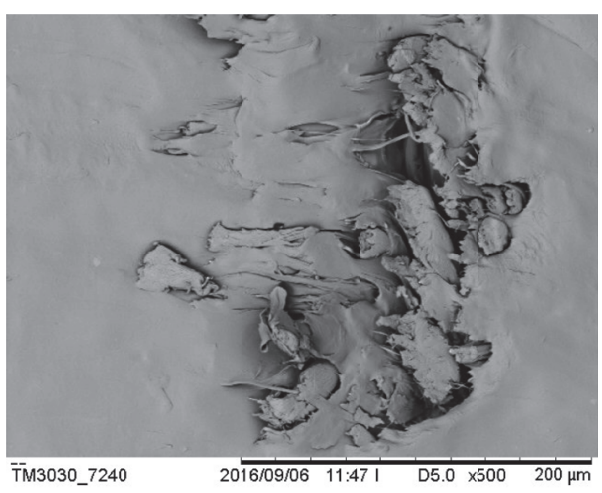

(c)

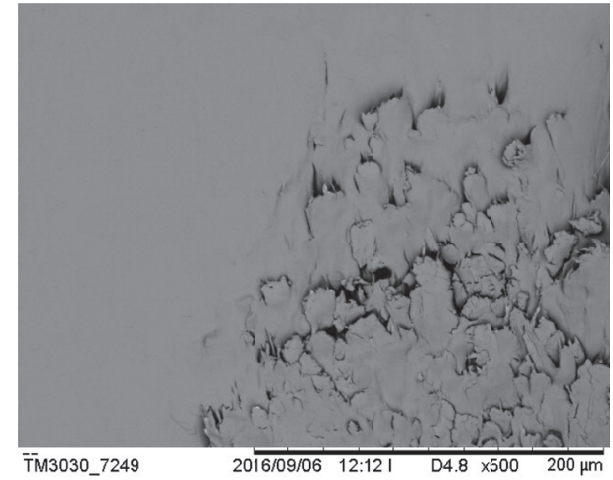

(b)

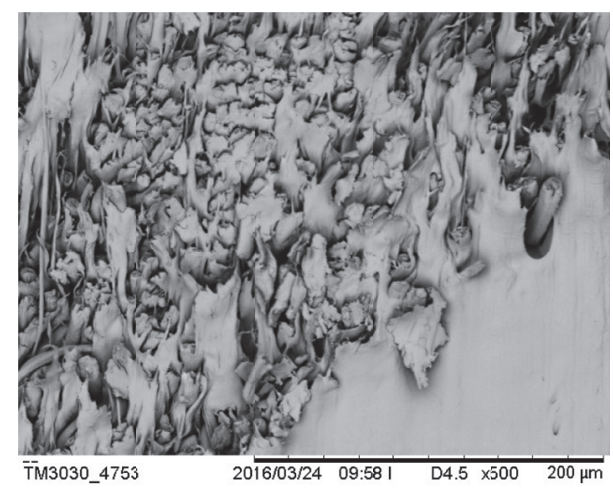

(d)

FIgURE 8: SEM images of the cross-section surface of (a) UJBC, (b) JCC, (c) BCC, and (d) JBCC at 10 wt\% fiber loading.

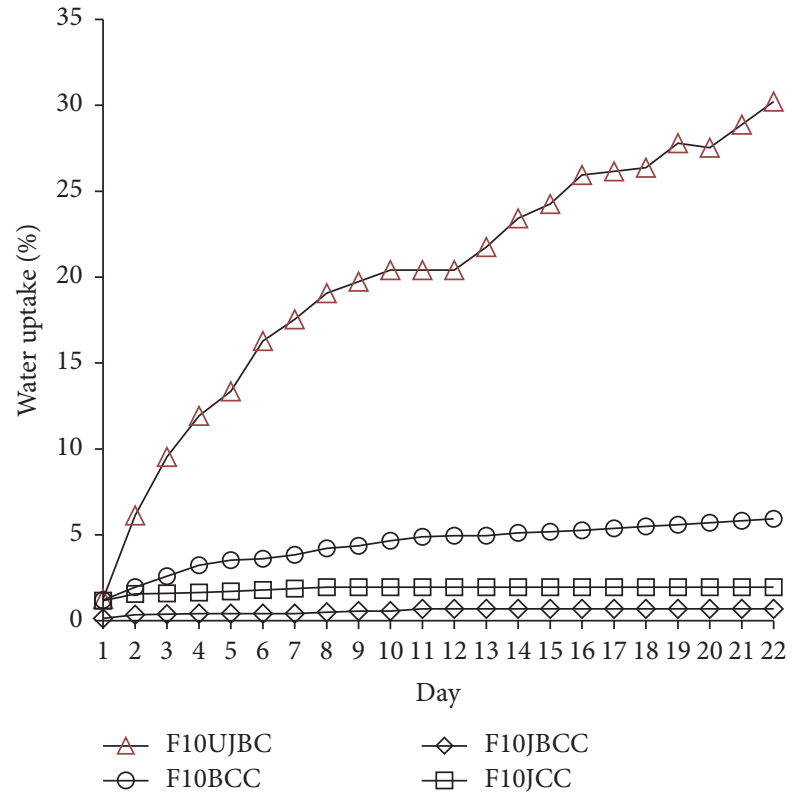

FIgURE 9: Water absorption percentage of UJBC, BCC, JBCC, and JCC for 22 days for $10 \mathrm{wt} \%$ fiber loading.

absorption is $5.9 \%$ and absorption rate reduced only after 10 days. This is mostly due to high surface porosity of bamboo cellulose combined with microvoid among treated cellulose and matrix interfaces. Overall, water absorption was significantly low for all treated cellulose hybrid composites compared with untreated hybrid fiber composite.

\section{Conclusions}

The present study reveals that both treated jute and bamboo cellulose were successfully used as reinforcement fiber in hybrid composites. The FTIR results show that jute and bamboo cellulose obtained are identical to commercial cellulose. The tensile strength and Young's modulus of hybrid cellulose composite are optimized at $10 \mathrm{wt} \%$ hybrid fibers loading. JBCC at $10 \mathrm{wt} \%$ reveals high tensile strength and Young's modulus increased by $157 \%$ and $195 \%$, respectively. All treated cellulose hybrid composites showed high onset decomposition temperature ranging from 346 to $415^{\circ} \mathrm{C}$ due to elimination of hemicellulose. F10JBCC shows 2.5 times higher activation energy followed by F10BCC and F10JCC at 2.0 times and 1.1 times, respectively. Water absorption was significantly low for all treated cellulose hybrid composites compared with untreated hybrid fiber composite. F10JBCC shows lowest water absorption up to 43 times lower compared to F10UJBC. The significant improved mechanical and morphological properties of treated cellulose hybrid composites are further supported by SEM images that show better matrix-fiber interaction compared to untreated hybrid fiber composite. The outcome of the composite shows cellulose 
hybrid composite suitable for outdoor application such as street light enclosure, automobile signal light cover, and playground slides.

\section{Conflicts of Interest}

The authors declare that there are no conflicts of interest regarding the publication of this paper.

\section{Acknowledgments}

The authors would like to acknowledge the Center of Excellence and Renewable Energy (CoERE), UNIMAS for their financial support, Grant no. CoERE/Grant/2013/06 and Ph.D. seed fund F02(DPP30)/1245/2015(05). The authors would like to thank Forestry Department Sarawak for their technical support on tensile testing.

\section{References}

[1] G. Bogoeva-Gaceva, M. Avella, M. Malinconico et al., "Natural fiber eco-composites," Polymer Composites, vol. 28, no. 1, pp. 98107, 2007.

[2] H. Ku, H. Wang, N. Pattarachaiyakoop, and M. Trada, "A review on the tensile properties of natural fiber reinforced polymer composites," Composites Part B: Engineering, vol. 42, no. 4, pp. 856-873, 2011.

[3] V. K. Thakur and M. K. Thakur, "Review: processing and characterization of natural cellulose fibers/thermoset polymer composites," Carbohydrate Polymers, vol. 109, pp. 102-117, 2014.

[4] H. Wang, L. Huang, and Y. Lu, "Preparation and characterization of micro- and nano-fibrils from jute," Fibers and Polymers, vol. 10, no. 4, pp. 442-445, 2009.

[5] P. Chaowana, "Bamboo: an alternative raw material for wood and wood-based composites," Journal of Materials Science Research, vol. 2, no. 2, pp. 1-13, 2013.

[6] H. P. S. Abdul Khalil, I. U. H. Bhat, M. Jawaid, and etal., "Bamboo fibre reinforced biocomposites: a review," Materials \& Design, vol. 42, pp. 353-368, 2012.

[7] C. Fuentes, G. Brughmans, L. Q. N. Tran et al., "Mechanical behaviour and practical adhesion at a bamboo composite interface: physical adhesion and mechanical interlocking," Composites Science and Technology, vol. 109, pp. 40-47, 2015.

[8] R. C. Sun, X. F. Sun, P. Fowler, and J. Tomkinson, "Structural and physico-chemical characterization of lignins solubilized during alkaline peroxide treatment of barley straw," European Polymer Journal, vol. 38, no. 7, pp. 1399-1407, 2002.

[9] Y. Liu and H. Hu, "X-ray diffraction study of bamboo fibers treated with $\mathrm{NaOH}$," Fibers and Polymers, vol. 9, no. 6, pp. 735739, 2008.

[10] T. Lu, S. Liu, M. Jiang et al., "Effects of modifications of bamboo cellulose fibers on the improved mechanical properties of cellulose reinforced poly(lactic acid) composites," Composites Part B: Engineering, vol. 62, pp. 191-197, 2014.

[11] Y. Xie, C. A. S. Hill, Z. Xiao, H. Militz, and C. Mai, "Silane coupling agents used for natural fiber/polymer composites: a review," Composites Part A: Applied Science and Manufacturing, vol. 41, no. 7, pp. 806-819, 2010.

[12] M. R. Ismail, A. A. M. Yassene, and H. M. H. Abd El Bary, "Effect of silane coupling agents on rice straw fiber/polymer composites," Applied Composite Materials, vol. 19, no. 3-4, pp. 409-425, 2012.

[13] J. Cai, P. Fei, Z. Xiong, Y. Shi, K. Yan, and H. Xiong, "Surface acetylation of bamboo cellulose: Preparation and rheological properties," Carbohydrate Polymers, vol. 92, no. 1, pp. 11-18, 2013.

[14] D. Ray, B. K. Sarkar, R. K. Basak, and A. K. Rana, “Thermal behavior of vinyl ester resin matrix composites reinforced with alkali-treated jute fibers," Journal of Applied Polymer Science, vol. 94, no. 1, pp. 123-129, 2004.

[15] X. Li, L. G. Tabil, and S. Panigrahi, "Chemical treatments of natural fiber for use in natural fiber-reinforced composites: a review," Journal of Polymers and the Environment, vol. 15, no. 1, pp. 25-33, 2007.

[16] S. Kalia, A. Dufresne, B. M. Cherian et al., "Cellulose-based bioand nanocomposites: a review," International Journal of Polymer Science, vol. 2011, Article ID 837875, 35 pages, 2011.

[17] L. F. Zemljic, O. Sauperl, T. Kreze, and S. Strnad, "Characterization of regenerated cellulose fibers antimicrobial functionalized by chitosan," Textile Research Journal, vol. 83, no. 2, pp. 185-196, 2013.

[18] P. B. Subhedar and P. R. Gogate, "Alkaline and ultrasound assisted alkaline pretreatment for intensification of delignification process from sustainable raw-material," Ultrasonics Sonochemistry, vol. 21, no. 1, pp. 216-225, 2014.

[19] J. Gassan and A. K. Bledzki, "Possibilities for improving the mechanical properties of jute/epoxy composites by alkali treatment of fibres," Composites Science and Technology, vol. 59, no. 9, pp. 1303-1309, 1999.

[20] M. Jawaid and H. P. S. Abdul Khalil, "Cellulosic/synthetic fibre reinforced polymer hybrid composites: a review," Carbohydrate Polymers, vol. 86, no. 1, pp. 1-18, 2011.

[21] S. Nunna, P. R. Chandra, S. Shrivastava, and A. K. Jalan, "A review on mechanical behavior of natural fiber based hybrid composites," Journal of Reinforced Plastics and Composites, vol. 31, no. 11, pp. 759-769, 2012.

[22] M. M. Rahman, M. R. Rahman, S. Hamdan, M. F. Hossen, J. C. H. Lai, and F. K. Liew, "Effect of silicon dioxide/nanoclay on the properties of jute fiber/polyethylene biocomposites," Journal of Vinyl and Additive Technology, 2015.

[23] K. P. Rajan, N. R. Veena, H. J. Maria, R. Rajan, M. Skrifvars, and K. Joseph, "Extraction of bamboo microfibrils and development of biocomposites based on polyhydroxybutyrate and bamboo microfibrils," Journal of Composite Materials, vol. 45, no. 12, pp. 1325-1329, 2011.

[24] M. Pöllänen, M. Suvanto, and T. T. Pakkanen, "Cellulose reinforced high density polyethylene composites-Morphology, Mechanical and thermal expansion properties," Composites Science and Technology, vol. 76, pp. 21-28, 2013.

[25] A. Sdrobiş, R. N. Darie, M. Totolin, G. Cazacu, and C. Vasile, "Low density polyethylene composites containing cellulose pulp fibers," Composites Part B: Engineering, vol. 43, no. 4, pp. 1873-1880, 2012.

[26] B. N. Kuznetsov, V. G. Danilov, S. A. Kuznetsova, O. V. Yatsenkova, and N. B. Aleksandrova, "Optimization of fir wood delignification by acetic acid in the presence of hydrogen peroxide and a TiO2 catalyst," Theoretical Foundations of Chemical Engineering, vol. 43, no. 4, pp. 499-503, 2009.

[27] "International A, ASTM D 638 Standard Test Method for Tensile Properties of Plastics. ASTM International, West Conshohocken, PA, USA, 2010". 
[28] International A, ASTM D 570 Standard Test Method for Water Absorption of Plastics. ASTM International, West Conshohocken, PA, USA, 1998.

[29] A. Alemdar and M. Sain, "Isolation and characterization of nanofibers from agricultural residues-wheat straw and soy hulls," Bioresource Technology, vol. 99, no. 6, pp. 1664-1671, 2008.

[30] J. I. Morán, V. A. Alvarez, V. P. Cyras, and A. Vázquez, "Extraction of cellulose and preparation of nanocellulose from sisal fibers," Cellulose, vol. 15, no. 1, pp. 149-159, 2008.

[31] R. Sukmawan, H. Takagi, and A. N. Nakagaito, "Strength evaluation of cross-ply green composite laminates reinforced by bamboo fiber," Composites Part B: Engineering, vol. 84, pp. 9-16, 2016.

[32] S. Y. Oh, I. Y. Dong, Y. Shin et al., "Crystalline structure analysis of cellulose treated with sodium hydroxide and carbon dioxide by means of X-ray diffraction and FTIR spectroscopy," Carbohydrate Research, vol. 340, no. 15, pp. 2376-2391, 2005.

[33] H. D. Nguyen, T. T. Thuy Mai, N. B. Nguyen, T. D. Dang, M. L. Phung Le, and T. T. Dang, "A novel method for preparing microfibrillated cellulose from bamboo fibers," Advances in Natural Sciences: Nanoscience and Nanotechnology, vol. 4, no. 1, Article ID 015016, 2013.

[34] M. C. Symington, W. M. Banks, O. D. West, and R. A. Pethrick, "Tensile testing of cellulose based natural fibers for structural composite applications," Journal of Composite Materials, vol. 43, no. 9, pp. 1083-1108, 2009.

[35] R. B. Yusoff, H. Takagi, and A. N. Nakagaito, "Tensile and flexural properties of polylactic acid-based hybrid green composites reinforced by kenaf, bamboo and coir fibers," Industrial Crops and Products, vol. 94, pp. 562-573, 2016.

[36] F. K. Liew, S. Hamdan, M. R. Rahman et al., "4-methylcatecholtreated jute-bamboo hybrid composites: effects of ph on thermo-mechanical and morphological properties," BioResources, vol. 11, no. 3, pp. 6880-6895, 2016.

[37] H. Yang, R. Yan, H. Chen, D. H. Lee, and C. Zheng, "Characteristics of hemicellulose, cellulose and lignin pyrolysis," Fuel, vol. 86, no. 12-13, pp. 1781-1788, 2007.

[38] S. Mohanty, S. K. Verma, and S. K. Nayak, "Dynamic mechanical and thermal properties of MAPE treated jute/HDPE composites," Composites Science and Technology, vol. 66, no. 3-4, pp. 538-547, 2006.

[39] A. Broido, "A simple, sensitive graphical method of treating thermogravimetric analysis data," Journal of Polymer Science Part A-2 Polymer Physics, vol. 7, no. 10, pp. 1761-1773, 1969.

[40] M. R. Rahman, S. Hamdan, A. S. Ahmed et al., "Thermogravimetric analysis and dynamic Young's modulus measurement of $\mathrm{N}, \mathrm{N}$-dimethylacetamide-impregnated wood polymer composites," Journal of Vinyl and Additive Technology, vol. 17, no. 3, pp. 177-183, 2011.

[41] R. Agrawal, N. S. Saxena, K. B. Sharma, S. Thomas, and M. S. Sreekala, "Activation energy and crystallization kinetics of untreated and treated oil palm fibre reinforced phenol formaldehyde composites," Materials Science and Engineering A, vol. 277, no. 1-2, pp. 77-82, 2000.

[42] S. Kumar, V. Choudhary, and R. Kumar, "Study on the compatibility of unbleached and bleached bamboo-fiber with LLDPE matrix," Journal of Thermal Analysis and Calorimetry, vol. 102, no. 2, pp. 751-761, 2010.

[43] M. F. Ashby and Y. J. M. Bréchet, "Designing hybrid materials," Acta Materialia, vol. 51, no. 19, pp. 5801-5821, 2003.
[44] Z. N. Azwa, B. F. Yousif, A. C. Manalo, and W. Karunasena, "A review on the degradability of polymeric composites based on natural fibres," Materials and Design, vol. 47, pp. 424-442, 2013.

[45] P. K. Kushwaha and R. Kumar, "Bamboo fiber reinforced thermosetting resin composites: effect of graft copolymerization of fiber with methacrylamide," Journal of Applied Polymer Science, vol. 118, no. 2, pp. 1006-1013, 2010.

[46] H. N. Dhakal, Z. Y. Zhang, and M. O. W. Richardson, "Effect of water absorption on the mechanical properties of hemp fibre reinforced unsaturated polyester composites," Composites Science and Technology, vol. 67, no. 7, pp. 1674-1683, 2007.

[47] S. K. Saw, G. Sarkhel, and A. Choudhury, "Surface modification of coir fibre involving oxidation of lignins followed by reaction with furfuryl alcohol: Characterization and stability", Applied Surface Science, vol. 257, no. 8, pp. 3763-3769, 2011. 

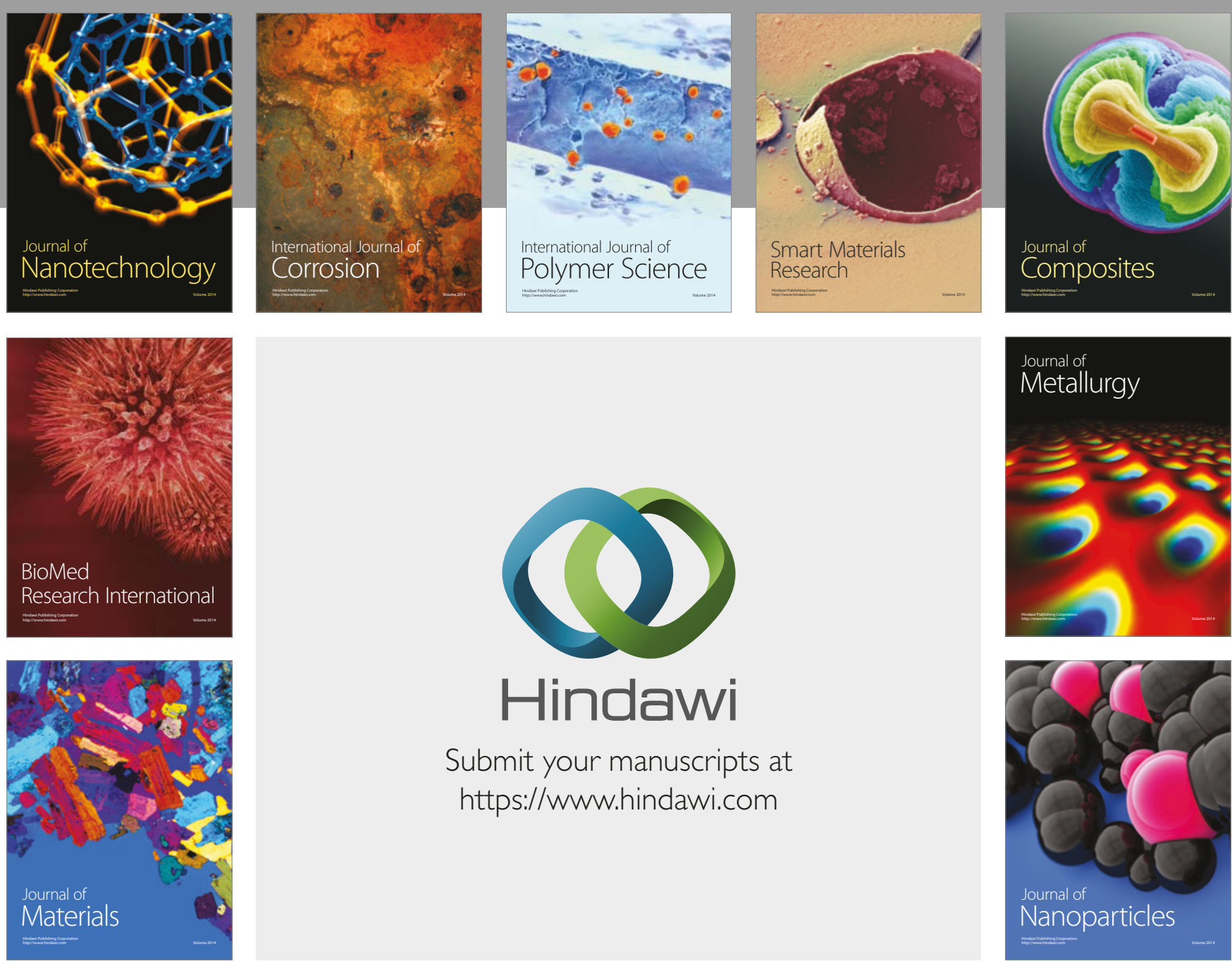

\section{Hindawi}

Submit your manuscripts at

https://www.hindawi.com
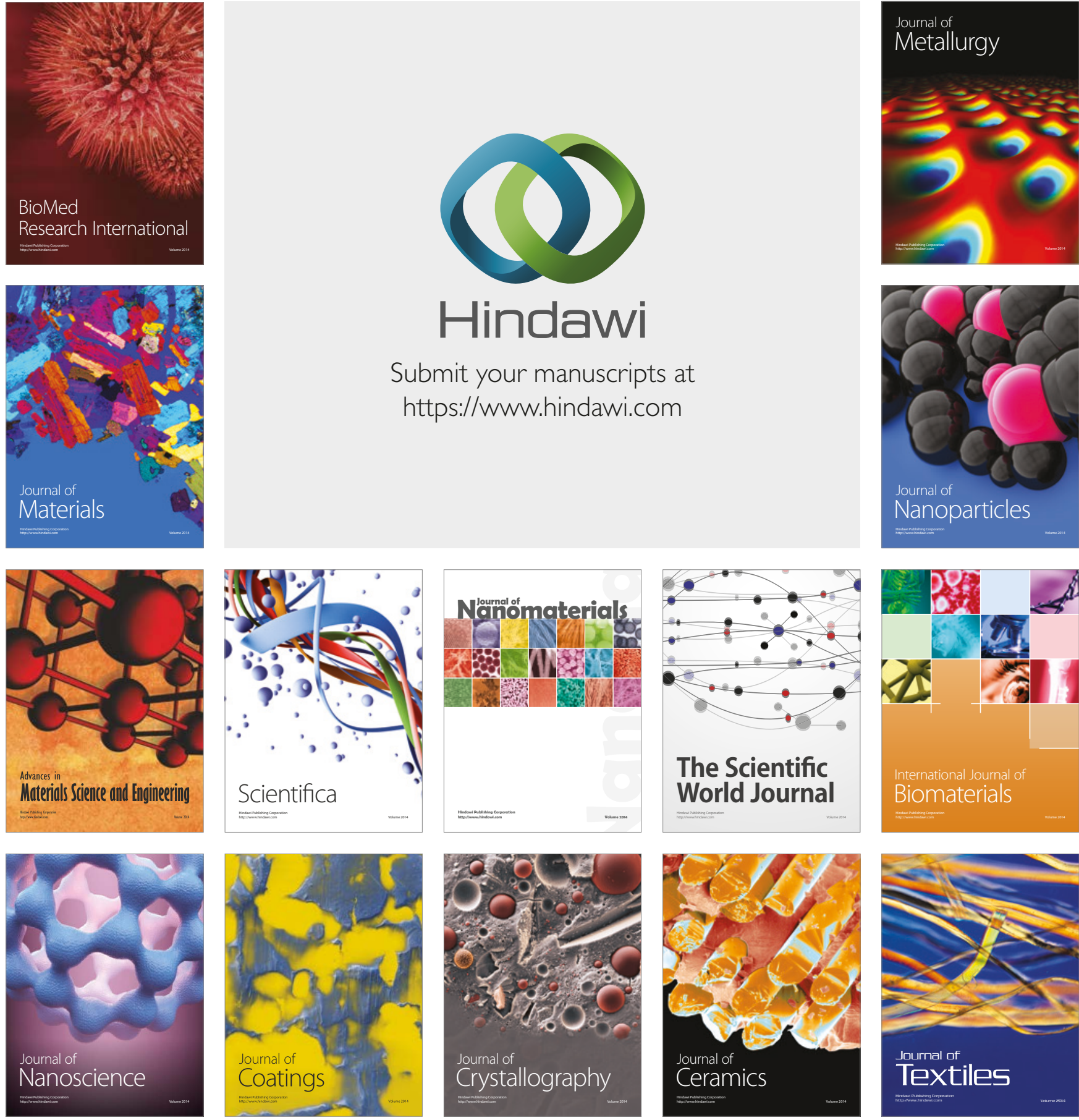

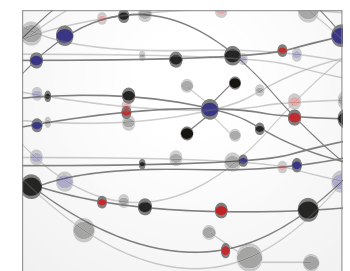

The Scientific World Journal
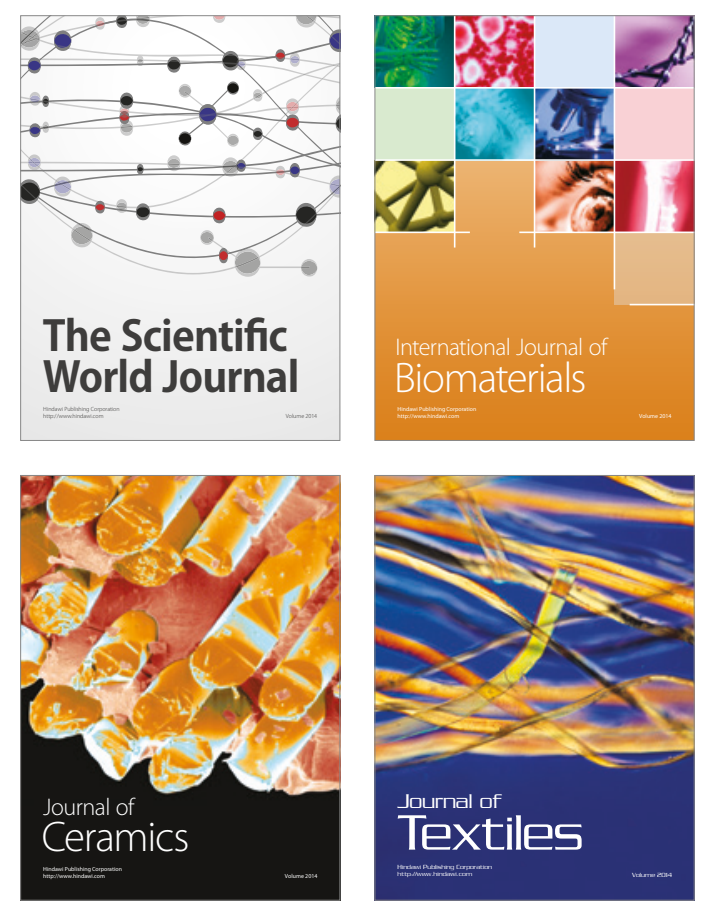